\title{
O Eviército na Campanha de Canudos
}

\author{
UMBERTO PEREGRINO \\ (Ten. Cel. Diretor da Biblioteca do \\ Exército)
}

\section{FISIONOMIA DO EXERCITO CHAMADO A COMBATER CONTRA OS JAGUNÇOS}

Exército com que contámos nos primeiros tempos da República, era maciçamente, entranhadamente, o velho exército profissional, herdado do Império, e cujas fileiras se povoavam com elementos de duas origens: voluntariado e recrutamente forçado.

Os voluntários eram, em geral, desocupados, quando não pessoas fugidas à ação policial ou à perseguição de alguma autoridade de atrabiliária; sòmente uns poucos seriam filhos de militares, que por vocação adotavam a carreira paterna, ou rapazes pobres que buscavam o Exército como meio de poderem estudar e elevar-se socialmente; havia ainda os "filhos-família" mal procedidos, que os pais alistavam no Exército, seguindo a tradição portuguêsa, como recurso para corrigi-los.

O recrutamento forçado, a que se recorria para cobrir a insuficiência do voluntariado, colhia para os quarteis, muitas vêzes elementos protegidos de pessoas influentes, o que levantava clamores de repercussão até no Parlamento. E então os Gabinetes, atendendo a êsses interêsses que thes afetavam a sorte eleitoral, agiam reduzindo ao mínimo os efetivos militares.

Resultava daí que as fileiras do Exército constituíam-se, na grande parte, com homens de condição humilde, que nelas se abrigavam da miséria, em geral gente de côr, como decorrência da posição que lhe tocava na estrutura econômico-social brasileira, naquelas alturas ainda soberanamente fundada na economia escravocrata e latifundiária.

Fazia-se sentir também a presença de elementos perturbadores, mes. mo perigosos, o que até certo ponto explica tenha perdurado, ainda pela República em fora, a prática do castigo corporal, que, não obstante, havia sido abolido, oficialmente, em 1874.

Dos elementos comuns, chegados aos quartéis, os melhores eram retidos pelo engajamento, renovado sucessivamente até a conta de 20 anos de serviço, quando a reforma estava assegurada.

A vida do quartel pautava-se pela rotina do serviço e da fachina. Varrer, lavar, acompanhar presos às fachinas, dar guarda e patrulhar, limpar os dou- 
rados, passar alvaiade nos correames brancos, lustrar as cartucheiras e a patrona, mediante receitas especiais, era tudo o que se fazia.

A instrução ocupava muito pouco das horas nos quartéis e assim mesmc consistia apenas na ordem unida, que predominava, no aprendizado de algumas regras de combate individual da época, na prática de carregar e travar as armas em uso. O treinamento de tiro não existia, nem seria possível realizá-lo, pois que as unidades não dispunham de instalaçốes para isso, consideradas, então, aparelhagem de luxo. Nessas condições, acontecia que homens servissem mais de 10 anos sem ter oportunidade de dar um tiro.

No depoimento do General KLINGER, oferecido naquelas preciosas "Narrativas Autobiográficas", a instrução constituía "acontecimento esporádico" e "era ministrada por atacado, em massa". Não havia incorporação regular anual, era o regime do portão aberto. "Não se imaginava - continua depondo o memorialista - que pudesse haver ano letivo, com matrículas em época certa". Um cabo, especialmente designado, encarrega-se-ia dos recru. tas. a uns seis meses decorridos, nunca antes, procedia-se a um exame que se referia, naturalmente, apenas à ordem unida. E também podia ser que não houvesse sequer êsse exame... Mas o certo é que ao fim de seis meses os recrutas passavam a prontos na instrução, o que, pràticamente, significava um diploma para concorrerem a todos os serviços.

"A tropa ociosa" - são também expressões do autorisado testemunho do General KLINGER - "era menoscabada pelos oficiais habilitados, de modo que os jovens cheios de sabença, egressos da escola, procuravam comissões de engenharia, o magistério militar, a burocracia reiúna ou lugar junto a algum alto comando", de sorte que só mesmo "os malucos ou os de todo pagãos" iam dar nalgum batalhão ou regimento "para se entediarem, jogar damas ou gamão, tomar café e palestrar, vencer antiguidade como menos canhões nos parques", enquanto irreverentes e descuidosas andorinhas "faziam ninho nas almas dos canhões", ao que informava ainda o mesmo General KLINGER.

'Mas, a melhor, a definitiva síntese dessa época está contida neste conceito famoso, formulado um dia, em momento de inspiração, por um oficial de cavalaria: vida".

"A Artilharia é ciência, a Cavalaria arte e a Infantaria... meio de

\section{INADEQUAÇÃO DOS MÉTODOS MAIS USADOS CONTRA CANUdOS}

Êsse quadro da organização do Exército à época em que se desenvolveu o episódio de Canudos EUCLIDES DA CunHA o fixou para demonstrar até que ponto foi êle responsável pelo fiasco e sacrifício das sucessivas Expedições. "Não tínhamos exército", di-1o Euclides com fundamento nestas considerações irretorquiveis:

"Não tínhamos exército na significação real do têrmo em que se inclui, mais valiosa que a existência de alguns milhares de homens e espingardas, 
uma direção administrativa, técnica e tática, definida por um Estado Ma1or enfeixando todos os serviços, desde a condução das viaturas aos lineamentos superiores da estrategia, órgão preparador por excelência das operações militares".

"Faltava tudo. Não havia um serviço de fornecimento organizado, de sorte que numa base de operações provisória, ligada ao litoral por uma estrada de ferro, foi impossível conseguir-se um depósito de víveres. Não havia serviço de transporte suficiente para cêrca de cem toneladas de munições de guerra".

"Por fim não havia soldados: os carregadores de armas, que ali desembarcavam, não vinham dos poligonos de tiro ou campos de manobra. Os batalhões chegavam, alguns desfalcados, menores que companhias, com o armamento estragado e carecendo das noções táticas mais simples. Era preciso completá-los, armá-los, vesti-los, municiá-los, adestrá-los e instrui-los".

Não há sequer exagêro de côres nesse quadro. Era assim rigorosamente, a máquina de guerra de que dispunhamos e da qual foram destacadas aquelas colunas de bravos, cujo destino veio a ser, invariàvelmente, a impotência e o extermínio nos caminhos que conduziam à cidadela de Antônio Conselheiro.

Mas não era só que fôsse retrógrada e mal aparelhada a organização militar brasileira ao tempo da campanha de Canudos, era ainda, de qualquer forma, inadequada ao tipo de luta que ali devia sustentar-se.

Do superado estágio técnico-profissional em que se encontrava o nosso Exército, dão pacífico testemunho os estudiosos que se têm ocupado da evolução militar brasileira. Em verdade, predominavam, no domínio da Tática, as Instruções de autoria do Coronel MOREIRA CÉSAR, aprovadas em 1894, e que se filiavam ainda à doutrina militar portuguêsa, assim mesmo, como. o indica o General PAULA CIDADE, "com grande atraso".

Nada, porém, mais expressivo a respeito do estágio em que se encontrava o Exército chamado a lutar em Canudos, do que a radical transformação que se operou na sua estrutura logo a seguir, isto é, a partir das manobras de 1905, promovidas pelo Marechal Hermes da Fonseca, e que se completaria com a sua lúcida e vigorosa ação à frente do Ministério da Guerra .

Mais, entretanto, que a doutrina retardatária, que o deficiente treinamento da tropa combatente, responde pelos desastres que se reiteraram ao embate com os fanáticos de Antônio Conselheiro, a inadequação dos meios e dos métodos empregados pelo Exército naquela campanha peculiaríssima, consoante, aliás, o assinalou insistentemente EUCLIDEs DA CUNHA, em flagrantes irrecorríveis. E' o que procuraremos ilustrar com elementos recolhidos ao longo das páginas de "Os Sertões".

As concentrações, para começar pelo comêço, eram assim efetuadas:

"As tropas convergiam na Bahia. Chegavam àquela capital em batalhões lestacados e seguiem imediatamente para Queimadas. Esta medida além de corresponder à urgência de uma organização pronta naquela Vila - 
feita base de operações provisórias - impunha-se por outro motivo igualmente sério. E' que, generalização de um conceito falso, havia no ânimo dos novos expedicionários uma suspeita extravagante a respeito das crenças monárquicas da Bahia. Ali saitavam com a altaneira provocante de triunfadores em praça conquistada. Aquilo, preestabelecera-se, era um Canudos grande".

"A paixão patriótica roçava, derrancada, pela insânia. A imprensa e a mocidade do norte, afinal, protestaram e, mais eloquente que as mensagens então feitas, falava em tôda a parte o descontentamento popular, prestes a explodir. Assim, como medida preventiva, os batalhões chegavam, desembarcavam, atulhavam os carros da Estrada de Ferro Central e seguiam logo para Queimadas".

Dos planos de campanha, perfilhados pelas diversas expedições, também são completas as informações de EUCLIDES DA CUNHA, que os submete, no que vão sendo enunciados, a rigorosa crítica comparativa.

Fala, por exemplo, da orientação que o General Solon desejava impor à segunda Expedição, e que não conseguiu em virtude das suscetibilidades autonomistas dơ Govêrno baiano:

"O comandante do Distrito compreendera a situação. Planejara atacar a revolta por dois pontos, fazendo que avançassem para o objetivo único não uma, mas duas colunas sob a direção geral do coronel do $9 .^{\circ}$ de Infantaria, Pedro Nunes Tamarindo. Era um plano compatível com as circurstâncias da luta: estabelecer antes de tudo um cêrco à distância; bater os-insurretos parceladamente e apertá-los, ao cabo, em movimentos envolventes de fôrças pouco numerosas e adestranlas. Realmente, libertas, estas, da morosidade própria às grandes massas, ajustar-se-iam melhor às escrabosidades do terreno, e do mesmo passo enfraqueceriam tôdas as causas de insucesso. Por outro lado, por mais original que seja o método combatente dos matutos, guerrilheiros impalpáveis dentro da tática estonteadora da fuga! - rola todo neste círculo único. Não se desenvclve num plano qualquer permitindo dar aos grupos dispersos o centro unificador de um objetivo prefixado. Atacálos, atraindo-os para diferentes pontos, é vencê-los".

Não foi isso, em todo caso, o que se fêz. "O comandante - explica o histcriador-militar de "Os Sertões" - limitou-se a formar três colunas e a ir para a frente, pondo diante da astúcia sutil dos jagunços e potência ronceira de três falanges compactas - homens inermes carregando armas magnifiças".

O plano de MOREIRA CÉSAR é definido com um rigor que poderiamos julgar exagerado, se o trágico desastre que o corôou não fôsse tão expressivo:

"Nada se resolveu de acôrdo com as circunstâncias especialíssimas da emprêsa. Ficou dominando tôdas as decisões um plano único, um plano de dcilegado policial enérgico: lançar à marche-marche mil e tantas baionetas dentro de Canudos. Isto no menor tempo possível".

Passam, depois, pela mesma apresentação explicativa de EUCLIDES, cs princípios que orientaram a ação da quarta massa militar arrojada contra 
Canudos: "Ao invés do cêrco à distância - lê-se em "Os Sertões" - para o que eram suficientes aqueles dezesseis batalhões, articulando-se em roda do arraial, planejara-se investir com os fanáticos por dois pontos, seguindo uma das colunas, a primeira, por Monte Santo enquanto a segunda, depois de reunida em Aracaju, atravessaria Sergipe até Geremoabo. Destas vilas convergiriam sôbre Canudos". Ora, tal plano, denuncia o analista, sem se deter, era "cópia ampliada de erros anteriores, com uma variante única: em lugar de uma eram duas as massas compactas de soldados que iriam tombar, todos a um tempo, englobados, nas armadilhas da guerra sertaneja. E quando, agitando as mais favoráveis hipóteses, isto não acontecesse, era fácil verificar que a plena consecução dos itinerários preestabelecidos, problematizava ainda um desenlace satisfatório da campanha".

"A simples observação de um mapa ressaltava que a convergência predeterminada, embora se realizasse, não determinaria o esmagamento da rebelião, mesmo à custa do alvitre extremo e doloroso da batalha".

E prossegue fazendo aquilo que devera ter sido empreendido, prévia e mais perfeitamente ainda, pelos Estados Maiores responsáveis, então, pela campanha - o estudo das estradas escolhidas e de tôdas as hipóteses possíveis sôbre a conduta dos jagunços, o que conduziria, fatalmente, à previsão transformada mais tarde em realidade, de que não seria possível subjugá-los, porquanto ficariam, como ficaram, com "mil portas por onde comunicaram com as cercanias e abastecerem-se à vontade".

O historiador militar não estaca na caracterização do êrro, indica logo a que denomina "um corretivo único: uma terceira coluna, que, partindo de Joazeiro ou Vila Nova, e vencendo uma distância equiparada às percorridas pelas outras, com elas convergisse, trancando a pouco e pouco aquelas estradas, originando por fim um bloqueio efetivo".

\section{O TERRENO E OS ABASTECIMENTOS}

Dois fatores de proeminente responsabilidade no desconcertante desenvolvimento da campanha de Canudos foram o terreno e os abastecimentos.

A respeito do terreno cumpre ressaltar, antes de mais nada, o papel unilateral da vegetação sertaneja. As caatingas, no dizer de EUCLIDES DA CuNHA, "são um aliado incorrutível de sertanejo em revolta. Entram também de certo modo na luta. Armam-se para o combate; agridem. Trancam-se, impenetráveis, ante o forasteiro, mas abrem-se em trilhar multivias, para o matuto que ali nasceu e cresceu".

As diversas nuances em que se desdobram as terras sertanejas - ora maciamente arenosas ora ásperas de pedregulho; ora calmas, espichando-se em boas chapadas, ora revoltas, orgia de cerros abrutos, 'que só os cabritos escalam; as estradas, as gargantas, os cursos dágua, tudo enfim, que constitui o terreno transitado pelas expedições, talado pelas patrulhas, sacudido pelos combates, ocupado durante $\alpha$ sítio, todo êsse terreno, tôda essa natureza estranha e bravia foi reproduzida em "Os Sertões" minuciosamente, rigorosamente, de uma forma que podemos denominar a topografia verbal de Eu- 
clides, porque, em verdade, pouco faltaria a quem quizesse compor uma carta topográfica daquelas regiões, partindo da leitura das suas páginas.

O problema dos abastecimentos, entrosado indissolùvelmente com a organização de bases de operações e de vias de comunicação seguras e suficientes, fci, outrossim um dos temas centrais no debate euclideano da campanha de Canudos. Desde ơ seu "Diário" se manifestam as lúcidas idéias de EuClides nesse particular. E, em "Os Sertões", não cessa de desenvolvê-las, atacando-as de todos os ângulos, mas sobretudo pintando as duras conseqüiências dos erros cometidos, como nesta passagem:

"O comando em chefe, sem carretas para o transporte de munições, desaparelhado dos mais elementares recursos, quedava-se, sem deliberar, diante da tropa acampada e mal avitualhada por alguns bois magros e famintos espalhados em tôrno sôbre as macegas secas das várzeas. O deputado do Quartel-Mestre-general não conseguira sequer um serviço regular de comboios, que partindo de Queimadas abastecessem a base das operações, de modo a armazenar reservas capazes de sustentar por oito dias a tropa".

Por fim, exteriuado de palmilhar aquele vasto itinerário de erros tão grosseiros quanto criminosos, que fori a campanha de Canudos, no tocante a abastecimentos, quando chega o instante de saudar a solução do problema, afinal vislumbrada e perseguida obstinadamente, até a execução, pelo Marechal Machado Bittencourt, EUCLIDES DA CUNHA exprime-se de uma forma que é quase uma explosão:

"Aquela campanha cruenta e na verdade dramática, só tinha uma sơlução e esta singularmente humorística. Mil burros mansos valiam na emergência por dez mil heróis. A luta com todo o seu cortejo de combates sangrentos, descambava, deploràvelmente prosaica, a um plano obscuro. Dispensava o heroismo, desdenhava o gênio militar, excluia o arremesso das brigadas, e queria tropeiros e muares. O mais caluniado dos animais ia assentar, dominadoramente, as patas entaloadas em cima de uma crise, e esmagá-la... Ademais sòmente êles podiam dar às operações a celeridade exigida pelas circunstâncias".

\section{MALOGRÁdOS ATAQUES A CANUdOS}

No que tange às operações de combate não foram menos graves nem menos copiosos os erros perpetrados. Referindo-se ao fatal assalto de Moreira César à cidadela dos fanáticos, observa EUCLIDES que se adotou "a mais rudimentar das ordens de combate, a ordem paralela simples, feita para os casos excepcionalíssimos de batalhas campais, em que a superioridade do número e da bravura excluindo manobras mais complexas, permitam, em terreno uniforme, a ação simultânea e igual de tôdas as unidades combatentes".

"Ali era inconceptível. Centralizada pela eminência coroada de canhões, a frente do assalto tinha, ao lado umas de outras, formas topográficas opostas: à direita, breve área de nível, facultando investida fácil porque c rio, naquele ponto, além de raso, corre entre bordas deprimidas; à esquerda, a 
terra mais revolta descaindo em recortes resvalantes e separada do arraial por um fosso escavado e fundo. A observação mais rápida indicava, porém, que estas disposições da extrema esquerda sendo de todos desfavoráveis para lutadores que devessem percorrê-las ràpidamente correndo para o assalto, eram, por outro lado, elemento tático de primeira ordem para uma reserva que ali estacionasse, de prentidão, destinando-se à diversão ligeira ou a in tervir oportunamente, segundo as modalidades ulteriores do recontro. Dêste modo, o relêvo geral do solo ensinava, por si mesmo, a ordem oblíqua, simples ou reforçada numa das alas, e, ao invés do ataque simultâneo, o ataque parcial pela direita firmemente apoiado pela artilharia, cujo efeito, atirando acêrca de pouco mais de cem metros de inimigo, seria fulminante".

"Além disto, não havia mais surpresas naquela luta e, caso o adversário. desdobrasse, de subito, inesperados recursos de defesa, as tropas de refôrço, agindo fora do círculo tumultuário do combate, poderiam mais desafogadamente mover-se segundo as eventualidades emergentes, em manobras decisivas, visando objetivos firmes. O coronel Moreira César, porém, desdenhara essas condições imperiosas e arrojanda à batalha tôda a sua gente, parecia contar menos com a bravura do soldado e competência de uma oficialidade leal que com uma hipótese duvidosa: o espanto e o terror dos sertanejos em fuga, colhidos de improviso por centenas de baionetas".

Outra amostra da impropriedade com que eram conduzidas as operações dà campanha de Canudos está na marcha da opulenta coluna do General Artur Oscar, assim descrita e analisada em "Os Sertões".

"As tropas partiriam da base de operações - à meia ração. Seguiriam chumbadas às toneladas de um canhão de sítio. E avançariam em brigades cujos batalhões, a quatro de fundo, guardavam escasso intervalo de poucos - metros".

"Persistia a obsessão de uma campanha clássica. Mostram-na as instruções entregues, dias antes, aos comandantes de corpos. Resumo de uns velhos preceitos que cada um de nós, leigos no ofício, podemos encontrar nas páginas do Viâl, o que em tal documento se depara - é a teimosia no imaginar, impactos, dentro de traçados gráficos, as guerrilhas solertes dos jagunços".

"O chefe expedicionário alongou-se exclusivamente numa distribuição de formaturas. Não se preocupou com o aspecto essencial de uma campanha que, reduzida ao domínio estrito da tática - se resumia no aproveitamento do terreno e numa mobilidade vertiginosa. Porque a sua tropa mal distribuída ia seguir para o desconhecido, sem linhas de operações - adstrita aos reconhecimentos ligeiros anteriormente feitos, ou dados colhidos, de relance, por oficiais das expedições passadas - e nada existe de prático naquelas instruções sôbre serviços de segurança na vanguarda e nos flâncos. Em compensação ostenta a preocupação da ordem mista, em que os batalhões, na emergência da batalha, se deveriam desenvolver, com as distâncias regulamentares, de modo que cada brigada. desarticulando-se em campo raso, pudesse, geomètricamente - cordões de atiradores. linhas de apoio e re- 
fôrço, e reservas - agir com a precisão mecânica estatuída pelos luminares da guerra".

O comandante da expedição estribava-se nas instruções de um sumo estrategista, Brun, as quais, continuava Euclides, "nada valiam porque estavam certas do mais", "A luta que só pedia um chefe esforçado e meia dúzia de sargentos atrevidos e espertos, ia iniciar-se enleada em complexa rêde hierárquica - uns tantos batalhões maciços entaladados em veredas flexuosas e emperrados diante de adversários fugitivos e bravos. Prendeuse-lhes além disto, às ilhargas, a mola de aço de um Withwort de 32 , pesando 1.700 quilos. A pesada máquina, feita para a quietude das fortalezas costeiras - era o entupimento dos caminhos, a redução da marcha, a perturbação das viaturas, um trambolho a qualquer deslocação vertiginosa de manobras".

Da parte dos jagunços também houve, naturalmente, erros e fraquezas, que Euclides, de resto, identifica, embora fôsse muito relativa essa apreciação, sabido como é que os guerrilheiros do arraial de Canudos não pelejavam segundo planos fixos, mas ao sabor do instinto, em ações individuais, empregando a astúcia, explorando a vantagem dơ conhecimento do terreno. O que thes dava unidade era ùnicamente o desígnio de destruir as colunas que se avizinhassem do arraial. Acontece, porém, que na noite de 18 de julho, após - assalto à cidadela sertaneja, ordenado pelo General Artur Oscar, e que resultaram numa situação extremamente perigosa para os atacantes, sem pơder avançar nem recuar, após terem conquistado com perdas alarmantes apenas uma fímbria de casas, os jagunços ficaram inertes, esperdiçando a oportunidade de obter um êxito definitivo sôbre essa nova expedição.

\section{DEPOIMENTO DO MAJOR FEBRÔNIO}

Mas, se dêsse plano analítico nos transportarmos ao fato concreto o deslocamento das colunas através daqueles chãos abrasados; o golpear sem pausa dos jagunços, ao longo dos caminhos; os estacionamentos sobressaltados; os furiosos e imponentes assaltos ao arraial; o castigo atroante dos Krupps; o desmantelamento sombrio das colunas em retirada; a rotina perigosa do sítio; os rasgos estarrecedores de bravura - também em "Os Sertões" depararemos páginas definitivas. Todavia quero oferecer-vos finalmente um depoimento especial, qual seja o do major Febrônio de Brito que comandou a 2.a Expedição contra Canudos e se portou com irrepreensível valor no perigoso choque com os jagunços, ao sopé da serra do Cambaio.

Eis como descreve êle, em carta datada de Monte Santo e dirigida ao Coronel Saturnino Ribeiro da Costa Júnior, Comandante do $3 .^{\circ}$ Distrito Militar, na Bahia, a ação do dia 19 de janeiro de 1897:

“Às 6 da manhã de 19, empreendi marcha para assaltar o foco dos celerados, quando repentinamente as avançadas e tôda coluna foram envolvidas por cêrca de 4.000 bandidos, produzindo indecisão nas fileiras nos primeircs momentos. Restabelecida a ordem, embora a falta de terreno para as manobras, a artilharia e fusilaria causaram de estragos medonhos, enquanto gru- 
pos de canibais se refaziam prodigiosamente. As fôrças e animais já se não alimentavam desde 17; os ferimentos se multiplicavam; mais 6 mortos contava a guarnição da artilharia, que já era puxada a pulso desde a trincheira, visto a falta de animais e fuga dos tropeiros, no dia anterior; munição esgotada; munição de fusilaria a extinguir-se, o obrigaram adotar a forma de quadrado para resistir ao ímpeto da agressão por todos os lados. Os bandidos, não tão mal armados, como se dizia, vinham morrer agarrados à arti. lharia. Nunca vi tanta ferocidade. Compreendendo o perigo da situação, baldo de recursos materiais, a fôrça se reduzindo, já havendo mais de 60 feridos e contusos, reuni oficiais em plena luta; e da opinião unânime dêles, foi resolvida a retirada, na impossibilidade de continuar a ação. Oportunamente, remeterei a ata da resolução. Tendo sido mortos muitos animais, reduzi a bagagem e organizei a retirada".

"Oficiais a pé, cedendo cavalos à feridos, puchavam canhões a pulso, sôbre pedreiras invencíveis, no percurso de 2 léguas. Comecei então o penoso trabalho de romper linhas inimigas à retaguarda. $O$ combate se prolongou até $6 \frac{1}{2}$ da tarde, quando pude salvar tudo e adquirir posição defensiva. Mesmo em ação, foram contados cêrca de 700 bandidos mortos. Retirada efetuada na melhor ordem; salvo tudo; inutilizado o armamento e munição que se encontravam com os bandidos, tive presente a cena da retirada do general Bourbaki, na fronteira Suíça, excluída a derrota. No dia 20 , alimentei ligeiramente as praças e empreendi penosíssima marcha para esta Vila. Se eu tivesse meios rápidos de mobilidade e pessoal suficiente, seria inevitável o triunfo".

"A força chegou dolorosamente extenuada, maltrapilha, quase nua, incapaz de qualquer trabalho. A artilharia e metralhadoras tinham muitas peças e parafusos de elevação inutilizados. Os únicos homens que informaram verdade foram o tenente-coronel Antônio Reis e vaqueiro Joaquim Calumby, que afirmaram que Conselheiro tem 8.000 homens. Pela média posso garantir que o número é superior a 5.000. Rogo comuniquais ao chefe de segurança. As fôrças tiveram lances de verdadeiro heroismo".

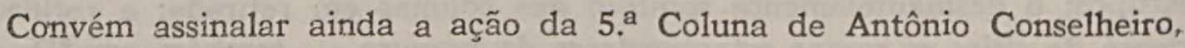
cujos "emissários solertes" não se distinguiam na "alaridade dos festejos" que iam em Monte Santo, com a presença das volumosas fôrças federais, mas tudo espiavam, tudo examinavam, calculavam o número de soldados, contavam as carretas, precipitando-se, em seguida, para a "aldeia sagrada", a comunicar ao Conselheiro e a Pajeu o resultado dêsse trabalho.

\section{AS GUERRILHAS NA HISTÓRIA MILITAR}

E foi assim, dessa convergência de dificuldades, de erros e de desvantagens que resultaram os desastres militares ocorridos em Canudos. Não vai neles, entretanto, nada de vergonhoso para o Exército, nada sequer que the tisne as gloriosas tradições. Vicissitudes iguais conheceram todos os exércitos de todos os tempos, sempre que se acharam em face de inimigos cujas carac- 
terísticas de luta transgrediam as regras clássicas de guerra. Foi o que sucedeu, aqui mesmo, ao sólido e aparatoso exército que a Companhia das Indias Ocidentais desembarcou um dia nas praias de Pernambuco e que teve de permanecer longamente imobilizado no Recife, prisioneiro da própria vitória, até que viesse a conhecer, por sua vez, alguns dos segredos que faziam o êxito da gente do Arraial do Bom Jesus, mas, nem as dificuldades iniciais que contiveram ás poderosas forças holandesas no solo pernambucano nem a derrota final que vieram a sofrer significaram algo irreparável para a sua reputação de combatentes. O mesmo fenômeno militar custaria ao exército inglês a severa experiência da guerra do Transwal, cujas lições Euclides da Cunha também focalizou. No futuro seriam os britânicos que se valeriam das operações de guerrilhas, fazendo desencadear a "Revolta Árabe", por intermédio de Lawrence, quando os turcos se colocaram ao lado da Alemanha, na Primeira Grande Guerra.

Paradoxalmente, o aperfeiçoamento da organização militar e o despótico acréscimo do seu potencial de destruição não vieram expulsar do quadro da guerra a ação dos guerrilheiros, mas, ao revés, vieram valorizá-lo e, daí, incorporá-la. Com efeito, na última Guerra Mundial os exércitos regulares, na França, na Itália, na Rússia, na Polônia, na China, nas Filipinas, na Birmânia, foram quase sempre coadjuvados por grupos dos chamados "partisans" e tais foram os resultados obtidos que, atualmente, as guerrilhas estão integralizadas na concepção da guerra total e os Estados Maiores já incluem nos seus planos o estímulo aos guerrilheiros e a coordenação da atividade dêles, bem como a neutralização das iniciativas inimigas nesse mesmo terreno.

Como se vê, o que aconteceu em Canudos foi um fenômeno de frequente incidência na História Militar. E, como observava Araripe Júnior, à margem da publicação de "Os Sertôes", era inevitável recebêssemos a lição da Canudos, "qualquer que fôsse o militar que para lá se dirigisse", dada a organização do exército que possuíamos, um "exército do litoral", para usar a sua própria expressão.

Assim se contam e explicam os aspectos mais expressivos do desenvolvimento militar da campanha de Canudos, em cuja voragem foram consumidas, uma após outra, três expedições militares, cada qual, sucessivamente, mais poderosa, e que só teve fim ao impacto esmagador da $4 .^{a}$ Expedição, um verdadeiro exército. E, como é sabido, Canudos não se rendeu, foi exterminado, a luta só cessou quando tombaram os seus últimos combatentes que eram quàtro: um velho, coxo por ferimento e usando uniforme da Guarda Católica, um rapaz de uns 16 anos, um preto alto e magro e um caboclo. Diante dêles 5.000 soldados, que vinham expugnando aquele reduto palmo a palmo, "na precisão integral do têrmo", como acentuou Euclides da Cunha. $\mathrm{E}$ ao serem afinal destocados da trincheira do centro responderam à intimação para deporem as armas investindo alucinadamente contra a fôrça maciça que os cercava. Um dêles, o preto, investia brandindo um machado... 